\section{Lady with erotic preference for diapers}

\section{Zack Cernovsky, ${ }^{1}$ Yves Bureau \\ 1Department of Psychiatry, 2Departments of Psychology and Medical Biophysics, University of Western Ontario, London, Canada}

\section{Abstract}

A patient in her 20s was referred to us for psychological assessment due to her depression and suicide attempts. She mentioned being anorgasmic except when diapered and emphasized her erotic preference for diapers. Her childhood included maternal deprivation in an impecunious family headed by an irritable physically disabled father on social assistance. Given the maternal deprivation in childhood, her erotic fixation on diapers parallels the emotional attachment to diapers observed by Harlow in mother deprived infant monkeys. Etiological hypotheses should also include the paradigm of avoidance learning from theories of behavior therapy. Our patient does not wish to change her sexual preference: in such cases, fetishism is not considered as an illness by DSM5. However, she needs to be treated for pathological levels of depression with suicidal ideation and low self-esteem.

\section{Introduction}

Our patient is a likable lady in her twenties, referred to us for psychological tests in the context of her recurrent depressive ideation and a history of suicide attempts. She explained that her erotic preference consists in wearing diapers and that she is anorgasmic except while diapered. She fantasizes about being in diapers and using a pacifier. In some of these fantasies, her diapers are being changed by benevolent others, or she is a schoolgirl in a classroom where all students are kept in diapers by a strict teacher, or she is one of diapered slaves.

Psychological reports on similar cases are too few, brief, and outdated. The published case studies usually dealt with males who engaged in unlawful or otherwise disruptive social conduct. Malitz ${ }^{1}$ examined a college student caught by the police while breaking into the home of a local family, due to a compulsive urge to find diapers to wear for erotic purpose and who was subsequently referred to psychiatric services. Dinello ${ }^{2}$ treated a diaper-wearing 17-year-old male referred by his parents due to acting out erotic fantasies about being a baby in diapers. He started wearing diapers since age 15 under his clothing. After the completion of treatment, he enrolled into a military school where he performed well.

Only with extreme rarity is the compulsion to wear diapers associated with pedophilia. Tuchman and Lachman's ${ }^{3}$ patient was a milkman, formerly a bouncer, referred to a psychiatrist after he was caught molesting his underage daughters.

Presumably numerous other more cautious persons, perhaps particularly women, skillfully find socially acceptable excuses of wearing diapers for non-medical reasons. For example, a group of adolescent females may agree to wear diapers as a prank in a bridal party, or in a college graduation party, and some of them even post their related video recordings of this on internet sites.

Hawkinson and Zamboni ${ }^{4}$ surveyed so called Adult Babies and Diaper Lovers via internet sites. Almost 2000 participated which suggests that erotic use of diapers is far more common than usually assumed by clinicians. Results indicated that the average frequency of wearing diapers as rated on a scale from 1 (never) to 7 (all the time) was 6.16 for males and 5.46 for females. The sexually stimulating value of diapers, as judged on the same scale from 1 to 7 , was rated at 5.86 by men and at 5.00 by women. This was an anonymous internet survey. Face-to-face case studies with scores on psychological tests are needed to advance our clinical understanding of erotic fixation on diapers.

\section{Case Report}

\section{Personal background}

Our patient described a harsh, emotionally deprived childhood in a Canadian metropolis. Her mother was an emotionally unbalanced drug addict with an untreated psychosis. The mother was usually absent, almost never involved in child care. Our patient and her siblings were raised by a disabled and unemployed father whose severe physical illness rendered him overly irritable, prone to outbursts of frustrated anger. As an infant, our patient lived in poverty. She witnessed parental fights with related physical injuries and experienced maternal deprivation.

In her early teens, our patient was frequently bullied by her classmates in school and by her siblings at home. Her school performance was poor. She would study and recalled the topics rather well. Unfortunately, her mind usually turned blank during exams and she failed. While in her classes, she withdrew into elaborate daydreams. In these daydreams, she was either a diapered slave or a child endowed with magical powers, evading evil forces within an
Correspondence: Zack Cernovsky, Department of Psychiatry, University of Western Ontario, 231 Wharncliffe Rd South, London, Ontario, Canada N6J 2 L3.

E-mail: drcernovsky@gmail.com

Key words: Diaper fetish; anorgasmia; avoidant conditioning; repetition compulsion; suicidal ideation.

Conflict of interest: the authors declare no potential conflict of interest.

Received for publication: 10 July 2016.

Revision received: 26 August 2016.

Accepted for publication: 26 August 2016.

This work is licensed under a Creative Commons Attribution-NonCommercial 4.0 International License (CC BY-NC 4.0).

(C) Copyright Z. Cernovsky, and Y. Bureau, 2016 Licensee PAGEPress, Italy

Mental Illness 2016; 8:6687

doi:10.4081/mi.2016.6687

austere and gloomy ambiance of emotional deprivation, similarly to plots in Harry Potter series. As an adult, she now still fantasizes about being a child in a school of magic powers where all students are kept in diapers. She presently writes such fiction stories as a hobby.

Our patient left her parental home in her late teens to live with an idle boyfriend. He took advantage of her financially and physically, was abusive, and ultimately broke up with her. Our patient described her frustration with the boyfriend's hurried coitus he performed on her in a self-centered style, ignoring her lack of physical enjoyment. He usually promptly left after his orgasm to resume his video games or conversations with his male friends. She lacked the courage and self-esteem, at the time, to request a modification of his coital routines to help her reach erotic arousal. In this context, our patient attempted suicide by readying herself to jump from a high rise building, i.e., via a rather lethal method. Her self-esteem still remains alarmingly low, partly also due to the social stigma of diaper fetishism. She said she hated herself.

\section{Results of personality tests}

Personality testing was requested from us by her psychiatrist as help in diagnosing and for pharmacological decisions. Our patient's profile on the Millon Clinical Multiaxial Inventory - III ${ }^{5}$ suggested depressive symptoms at the level of severity just below a major depressive episode, an underlying markedly schizotypal personality, with a subclinical tendency towards anxiety and cognitive slippage. The test data are consistent 
with a discouraged regressive social withdrawal into fantasies and daydreams in a sad and frustrated person. Her Rorschach ${ }^{6}$ suggested spontaneous or perhaps also impulsive behavior in an imaginative and potentially creative person with a history of self-esteem issues such as self-rejection. The score on the Pittsburgh Sleep Quality Index ${ }^{7}$ indicated a severe sleep impairment, with the sleep efficiency index of only $61.5 \%$. Insomnia has been shown to increase suicide risk. ${ }^{8}$ Her scores on vocabulary subtest of Wechsler Adult Intelligence Scale ${ }^{9}$ and Raven's Matrices ${ }^{10}$ were within the average category. Such cognitive tests essentially reflect skills usually acquired in academic settings where she so often intentionally de-focused her attention from classes, given the context of being bullied by classmates and mistreated at home. Her cognitive scores probably underestimate her intellectual and creative potential. Theories of divergent versus convergent thinking suggest that creativity does not necessarily require an above average academic record. ${ }^{11}$

\section{Discussion}

Our patient was aware of her erotic inclination already while 5 years old. The etiology of her fixation on diapers is probably related to formative experiences in her childhood. She grew up in an environment characterized by deprivation, bullying, and rejection. The effects of maternal deprivation are presumably similar to those observed in Harlow's laboratory studies on infant monkeys separated from their mothers. Harlow's team noted that when folded gauze diaper was placed on the floor of the cage, the mother-deprived infant monkeys tended to maintain intimate contact with its soft, pliant surfaces. Harlow ${ }^{12}$ wrote We were impressed by the deep personal attachments that the monkeys formed for these diaper pads, and by the distress they exhibited when the pads were briefly removed once a day for the purposes of sanitation. The behavior of the monkeys was reminiscent of the human infant's attachment to its blankets, pillows, rag dolls, or cuddly teddy bears.

Our patient did not recall any incidents of bed wetting as a child, however, most persons have only too fragmentary or unreliable memories before the age of 7 . It is feasible that she was mistreated for wetting her bed during that time span, or at an earlier age. We relied on the behaviorist theories of operant and classical conditioning to postulate the following etiological mechanisms for the fixation on diapers: After a child manages to stay dry for a few weeks or months, the caretakers might be upset if the bedwetting resumes, and at times mistakenly attribute this relapse to the child's wayward defiance or carelessness. If they treated the girl in aversive ways (nagging, scolding, ridiculing, beating) on such occasions, until they finally resigned themselves to diaper her again, and if the aversive stimulation stopped whenever she was placed in diapers because the bed sheets were now dry, the fact of again wearing diapers would have an addictive impact of bringing a major relief from impending punishments for something out of the girl's conscious control. This is predicted by behaviorist theory of avoidance conditioning. ${ }^{13}$ The avoidance conditioning proceeds independently of the person's awareness, it is a rather mechanical process, and is very resistant to extinction. This means that the diaper wearing or the compulsion to wear them can inflexibly persist over years or decades in the absence of aversive stimuli, those that originally followed bedwetting. Pavlovian conditioning 13 has probably also been involved by endowing diapers with an erotic value. This conditioning process is unlikely to be adequately conscious or reliably recalled by the patients.

It is very important to note that our behaviorist etiological hypothesis clearly implies that an erotic fixation on diapers can exist independently of any psychiatric pathology. The readers of our article should not assume that all fetishists show psychopathology such as depression, schizotypal traits, or suicide attempts as in the test data and personal history of our particular patient. Although fetishists as a group could perhaps have some particular common personality traits, these would not necessarily be of pathological nature. Statistical research with non-pathological personality tests on large samples of such persons is needed to clarify this issue.

The Freudian label of repetition compulsion $^{14}$ might also be evoked by some analysts for a fixation on diapers, however, it is usually applied to cases in which the obsessive repetition is dysphoric, more ego-dystonic, and less eroticized.

Diaper fetish could perhaps also be tangentially related to the frequent erotic fascination with urine soaked underwear as reported in recent studies. ${ }^{15,16}$

Our depressed, suicidal, and schizotypal lady is endowed with a vivid and elaborate imagination. Her withdrawal into daydreams was presumably an adaptive protective mechanism during her childhood while being treated harshly by those around her. Perhaps her fantasies about diapers and pacifiers symbolically express her need to be protected, mothered, and nurtured. At present, our patient, as a young adult, still fantasizes about her own variations on the Harry Potter theme. In her fantasies (and in her attempts at writing stories), she is in the school of magic powers where all students are kept in diapers and supervised by a stern and strict, yet not malev- olent teacher who trains them to defend themselves against ill-wishing witches. The atmosphere of her daydreams is austere, devoid of being loved by another person or emotionally connected to others by preponderantly positive ties. The existential-analytical approach promoted by Medard Boss ${ }^{17}$ may describe her subjective experience of being alive as permeated by an excessive distrust of others and a lack of supportive emotional ties. The psychotherapy of our patient has aimed at improving her selfesteem and at addressing her underlying lack of those social skills that are essential for developing mutually supportive interpersonal relationships. Her psychotherapy also aims at overcoming her deficits in intrapsychic coping skills for constructive processing of situational stress via other means than a regressive social withdrawal.

\section{Conclusions}

The value of our case study lies in providing a psychological background based on personality tests. The test results documented that our schizotypal patient has experienced a pathological level of depression and unresolved selfimage problems. These factors and also her insomnia jointly contribute to suicidal risk. ${ }^{8}$ The self-esteem of this emotionally fragile person was greatly undermined by stigma of fetishism. Such stigma, if internalized as a self-rejection or self-hatred, can severely exacerbate emotional distress in fragile psychiatric patients. Her psychotherapy has therefore aimed at improving her self-acceptance, her self-esteem, and at reducing her social isolation. A hurried insistence on therapeutically removing our patient's fixation on diapers would exacerbate rather than remedy her depressive symptoms and escalate her suicidal potential. The brief sexual re-orientation therapies do not have satisfactory success rates and may have an adverse impact on the patient's subjective quality of life ${ }^{18}$ or on the chance of long term survival. Psychiatric patients are especially vulnerable to such iatrogenic interventions.

Reiersøl and Skeid19 argued that fetishism should not be considered as an illness in the international classification of diseases. The DSM5 does not consider erotic use of fetishes per se as a disease or disorder, unless it causes a clinically significant distress or impairment in social, occupational, or other important areas of functioning. ${ }^{20}$ The DSM5 manual provides the following example: an individual whose sexual partner either shares or can successfully incorporate his interest in caressing, smelling, or licking feet or toes as an important element of foreplay would not be diagnosed with fetishistic disorder; nor would an individ- 
ual who prefers, and is not distressed or impaired by, solitary sexual behavior associated with wearing rubber garments or leather boots. ${ }^{20}$

Our patient has not wished to change her erotic preference. She has suffered from pathological levels of depressive symptoms, suicidal ideation, and low self-esteem. Unlike her fetishism, these pathological symptoms have required an urgent treatment. In our patient's ongoing psychotherapy, the emphasis on enhancing her social skills and on improving her self-esteem helps her to find emotionally supportive friends and perhaps also a suitable erotic partner with a compatible erotic preference.

\section{References}

1. Malitz S. Another report on the wearing of diapers and rubber pants by an adult male. Am J Psychiatry 1966;122:1435-7.

2. Dinello FA. Stages of treatment in the case of a diaper-wearing 17-year-old male. Am J Psychiatry 1967;124:94-6.

3. Tuchman WW, Lachman JH. An unusual perversion: the wearing of diapers and rubber pants in a 29-year-old male. Am J
Psychiatry 1964;120:1198-9.

4. Hawkinson K, Zamboni BD. Adult baby/diaper lovers: an exploratory study of an online community sample. Arch Sex Behav 2014;43:863-77.

5. Millon T, Millon C, Davis R, Grossman S. MCMI-III Manual. $4^{\text {th }}$ ed., Minneapolis, MN: Pearson Education, Inc.; 2009.

6. Rorschach H. Psychodiagnostics: a diagnostic test based on perception. Berne, Switzerland: Verlag Hans Huber; 1942.

7. Buysse DJ, Reynolds CF, Monk TH, et al. The Pittsburgh sleep quality index (PSQI): a new instrument for psychiatric research and practice. Psychiatry Res 1989;28:193213.

8. Littlewood DL, Gooding P, Kyle SD, et al. Understanding the role of sleep in suicide risk: qualitative interview study. BMJ 2016;6:e012113.

9. Wechsler D. Wechsler adult intelligence scale. San Antonio, TX: The Psychological Corporation; 1997.

10. Raven JC. Standard progressive matrices. London: H.K. Lewis \& Co; 1958.

11. Lunke K, Meier B. Disentangling the impact of artistic creativity on creative thinking, working memory, attention, and intelligence: evidence for domain-specific relationships with a new self-report questionnaire. Front Psychol 2016;7:1089.
12. Harlow HF. Love in infant monkeys. Sci Am 1959;200:68-74.

13. Passer MW, Smith RE, Atkinson, ML, et al. Psychology: frontiers and applications. $3^{\text {rd }}$ ed., Toronto: McGraw Hill; 2008.

14. Freud S. Jenseits des Lustprinzips (Beyond the Pleasure Principle). Leipzig, Wien, \& Zürich: Internationaler Psychoanalytischer Verlag; 1920.

15. Cernovsky ZZ. Fetishistic preferences of clients as ranked by a sex worker. J Sex Marital Ther 2016;42:481-3.

16. Scorolli C, Ghirlanda S, Enquist M, et al. Relative prevalence of different fetishes. Int J Impot Res 2007;19:432-7.

17. Boss M. The analysis of dreams. New York: Philosophical Library; 1958.

18. Bradshaw K, Dehlin JP, Crowell KA, et al. Sexual orientation change efforts through psychotherapy for LGBQ individuals affiliated with the Church of Jesus Christ of Latter-day Saints. J Sex Marital Ther 2015;41:391-412.

19. Reiersøl 0, Svein S. The ICD diagnoses of fetishism and sadomasochism. J Homosex 2006;50:243-62.

20. American Psychiatric Association. Diagnostic and statistical manual of mental disorders. $5^{\text {th }}$ ed., Washington, DC: American Psychiatric Publishing; 2013. 